\title{
Understanding Homeowners' Pricing Decisions: An Investigation of the Roles of Ownership Duration and Financial and Emotional Reference Points
}

\author{
Katherine E. Loveland • Naomi Mandel • \\ Utpal M. Dholakia
}

Published online: 18 April 2014

(C) Springer Science+Business Media New York 2014

\begin{abstract}
In this research, we examined the interactive effects of duration of ownership with both financial (change relative to purchase price) and emotional (accumulation of positive vs. negative memories) reference points on home sellers' initial asking prices and the stickiness of those prices. We found convergent results in a field study of house listings in four US markets (Phoenix, Minneapolis, Philadelphia, and Wilmington) and a laboratory experiment. In particular, we found that after a long ownership duration, sellers ask for higher prices when they are in the gains domain than in the losses domain (a reversal of Prospect Theory), whereas after a short ownership duration, sellers ask for lower prices when they are in the gains domain than when they are in the losses domain.
\end{abstract}

Keywords Reference points - Behavioral decision theory · Prospect Theory $\cdot$ Emotional reference point $\cdot$ Endowment effect $\cdot$ Home pricing

\section{Introduction}

In the decade spanning 1996 to 2006 , housing prices in the USA soared due to various reasons, such as low mortgage interest rates, aggressive lending policies, and governmental attempts to increase home ownership levels. Whereas home prices usually increase by $1.7 \%$ annually [1], they increased

K. E. Loveland $(\bowtie)$

HEC Montréal, Montréal, QC H3Z 2Y7, Canada

e-mail: kate.loveland@hec.ca

N. Mandel

Arizona State University, Tempe, AZ 85287, USA

U. M. Dholakia

Rice University, Houston, TX 77005, USA by approximately $85 \%$ (after adjusting for inflation) during this period, creating a speculative bubble [2]. From 2006 to 2011, falling housing values throughout the country affected millions of households, declining $40 \%$ from the peak [3].

During the housing crash, even as prices declined 15, 20, and even $30 \%$ from where they had been just a few short years earlier, a 12-month supply of homes remained for salea level that is twice that of a healthy market [4]. Many homeowners continued to ask unreasonably high prices (given market valuations at the time), and their reluctance to lower asking prices, also known as downward price stickiness, led to a glut of excess supply of as many as 6.2 million homes ([5]; Case \& Schiller [6-8]), prolonging the housing crisis [9]. Although the phenomenon of sticky asking prices has been well-documented, the psychology underlying such pricing decisions remains unclear.

Accordingly, in the present research, we examine the factors that lead homeowners to make decisions such as overpricing their homes and resisting downward price changes, which can be counterproductive in market downturns for both the financial health of individual homeowners and for the vitality of the housing market as a whole. Our goal is to contribute to the existing consumer decision-making research by examining key factors that interact to influence home sellers' price setting and concessionary behaviors in negotiations involving the sale of their homes. Specifically, we study how the duration for which the seller has owned the home combines with his or her financial and emotional gains or losses accumulated during the period of ownership to influence asking prices and the stickiness of those prices.

One of our contributions is to develop the notion of an emotional reference point, and to subsequently study the role of emotional gains and losses in decision making. In this research, we characterize emotional gains or losses as the store of positive or negative emotional memories accumulated by the homeowner during the period of home ownership. 
Specifically, we characterize individuals who have enjoyed predominantly positive experiences in their homes, and consequently are emotionally attached to the homes, as being in the domain of emotional gains, because ownership of the home has provided significant emotional utility. On the other hand, we characterize homeowners who have suffered predominantly negative experiences in their homes, and are consequently emotionally detached from the home, as being in the domain of emotional losses, because ownership of the home has provided significant emotional disutility.

By conceptualizing emotional gains and losses in this manner, we are able to make and test some unique predictions within the framework of Prospect Theory. Previous work that has sought to incorporate emotions into the framework of Prospect Theory has generally focused on the emotions related to outcomes, such as selling or keeping the endowed object. For example, in their exploration of the hedonic experience of loss aversion, Mellers and Ritov [10] focus on the predicted and experienced pleasure and pain of giving up an object. We take a different approach in the sense that we define an emotional loss or gain with respect to the experience of ownership itself, rather than in terms of the experience of giving up the object. By taking this perspective, we are able to take into account the fact that people who have had a positive emotional experience with an endowed object are already in the domain of gains before they have even begun the negotiation process. Furthermore, we are able to account for the potential effects of negative experiences of ownership, which place individuals in the domain of emotional losses, on pricing decisions.

Our study contributes to research on decision making by introducing the construct of emotional reference point, and by proposing and testing an account of seller valuation in which this emotional reference point interacts with the duration of ownership, in some cases leading to a reversal of the loss aversion effects predicted by the extant literature (e.g., [11]). To the best of our knowledge, this is the first paper to explicitly consider the impact of the emotional reference point associated with a specific object on its utility and its owner's subsequent valuation of it.

We have chosen to test our theory and examine our hypotheses in the context of real estate because home ownership involves significant investments, both financial and emotional, and thus provides an ideal context to examine the unique impacts of financial and emotional reference points on seller valuation.

\section{The Endowment Gap and Homeowner Valuation}

Research on Prospect Theory [11] has demonstrated that owners value an object to a much greater extent than do non-owners. This phenomenon, known as the "endowment effect," is defined as the tendency for the minimum selling price to exceed the maximum buying price in markets [12]. Considerable prior work has studied the endowment effect. For example, Strahilevitz and Loewenstein [13] found that an individual's selling price for a current possession increased as a function of how long the person had owned the object. These and other findings mainly focus on ownership and possession of relatively inexpensive items such as mugs and pens (e.g., $[14,15])$, and study ownership over short periods of time, usually spanning a few minutes. In contrast, in the current research, we study ownership of arguably one's most important possession, a home, over periods of years. In particular, we examine factors that influence both home sellers' initial asking prices and their reluctance to lower these prices. While prior researchers have identified moderators that magnify loss aversion, such as involvement [16], a threat to the person's social self [14] or relationship norms [17], we instead investigate circumstances under which loss aversion might be reversed. In particular, we show that in the case of long ownership duration (measured in years, rather than minutes), sellers find it more painful to offer concessions when they are in the domain of gains than when they are in the losses domain.

In this research, we focus exclusively on sellers' prices, rather than the difference between buyers' and sellers' prices (referred to as the "endowment gap"). The prior literature suggests that buyers tend to be more focused on average selling prices (and thus are more economically rational) when formulating their offers, while sellers are more likely to be influenced by personal factors such as their purchase price, accumulated memories, and duration of ownership. For example, Carmon and Ariely [18] suggest that buying and selling price estimates reflect a focus on what the consumer forgoes in the potential exchange, so that buyers and sellers differ not only in their valuations of the same item but also in how they assess its value. Irmak et al.[19]) show that sellers construe products at a higher level (i.e., in more abstract terms) than buyers do. Buyer prices are heavily influenced by salient reference prices (such as recent comparable home sales), and seller prices are influenced by the benefits of possessing the item (such as positive memories engendered by the item).

Taken together, the prior literature appears to suggest that sellers, compared to buyers, are more susceptible to emotional factors (and are thus less rational) when setting prices. Furthermore, prior research has shown that over repeated trials, sellers are more likely to capitulate than buyers [20], suggesting that the endowment effect may be primarily driven by sellers' biased (over)estimates about how much money they should ask for. Interestingly, the status quo in the US housing market seems to suggest price stickiness is a result of sellers' refusal to lower prices in line with the changed market conditions (e.g., [21,22]). Thus, we hope to ascertain the factors 
underlying the sellers' asking prices and their reluctance to concede in the negotiation, resulting in the downward price stickiness evident in such markets.

The economics literature defines "stickiness" as price rigidity; a high level of price stickiness means that selling prices fail to react quickly to changing market conditions (e.g., $[23,24])$. In the housing market, Case and Quigley [5] give the example of sticky prices in which demand drops (e.g., when home buyers stop looking for houses or making offers), but sellers maintain their asking prices, resulting in a sharp drop in the number of homes sold. In this research, we measure price stickiness both with respect to how quickly sellers drop prices and the amount by which they do so.

Based on the literature, we have identified two factors that we expect to interact to determine sellers' asking prices and the stickiness of these prices: (1) whether the seller has experienced a gain or loss (either financial or emotional) and (2) the duration of home ownership. We selected these two factors based on prior research that has demonstrated the importance of changes from reference points [11] and the duration of ownership [13] on valuation of owners. When contemplating selling a home, a possession that they interact with on an intimate and daily basis, owners are likely to reflect on their history in the home, leading to heightened salience of investments in the home, both emotional and financial. In the following sections, we build on the relevant literature to predict how these factors will influence sellers' asking prices for their homes.

\section{Financial Reference Point and Ownership Duration Effects}

According to Prospect Theory [11], individuals evaluate their current state in terms of gains or losses relative to a reference point. For example, home sellers are likely to view their home's purchase price as a reference point, compared to which they have either earned or lost money. Most homeowners expect to sell their homes for more than they paid for them. In a stable housing market, this is usually the case because people do not sell homes very often, and the sale price is usually higher than the purchase price simply due to inflation [25]. Furthermore, many people buy houses on credit, and the resulting leverage can often result in significant real investment gains [25]. In a downmarket, unrealistic expectations about investment gains may cause sellers to continue to hold out for unrealistic asking prices [26]. Therefore, consistent with Prospect Theory, we expect individuals to be less likely to hold out for a higher price when they are in the gains domain (i.e., they have made a profit on their home) than when they are in the loss domain (i.e., they have lost money on their home), because a lower starting price in the gains domain will not loom as large as one in the loss domain. Figure 1a illustrates the expected utility curve, where a concession in the gains domain results in a smaller loss in utility compared to a concession in the loss domain [11].

More important to our theory, we expect an interaction between the homeowner's financial reference point and ownership duration. In particular, we expect that a longer duration of ownership will cause homeowners to demand higher prices because the homeowner has an expectation of making a financial gain on the house, and anything less than the expected gain might be framed as a loss [27]. Negotiators often use social information to form reference points (such as neighbors' home sale prices during an upmarket), even when such information should not be relevant to the decision [28]. Further, they may use such information to form expectations about the "fairness" of expected outcomes [29]. In addition, people prefer improving sequences of outcomes over declining sequences of outcomes [30], so they are more likely to respond unfavorably to a concession (i.e., a decline) when they are already in the gains domain than when they are in the losses domain.

Figure $1 \mathrm{~b}$ illustrates the case of a longer duration of ownership, in which the expected utility curve has shifted to the right due to increased seller expectations [31,32]. With the new curve, a concession in the gains domain results in a larger loss of utility than a concession in the loss domain, making long-term sellers hesitant to lower their prices. Because longterm owners expect to make a profit, those in the domain of financial gains will generally set a higher initial asking price than those in the domain of financial losses, as they consider both the time and monetary investment they have made and expect to be reimbursed for. Furthermore, because homes are often viewed as investments [25] that are expected to accrue value over time, sellers are likely to expect higher returns the longer they have been in their home, particularly when they are in the domain of financial gains. While buyers focus on both positive and negative aspects of an item for sale, sellers tend to focus only on the benefits of ownership [18], and may expect to be compensated for giving up those benefits [15]. Sellers who have lived in their homes for a long period of time have likely become accustomed to the benefits of living in that home, resulting in a reference point shift [32,33]. Consequently, we predict that when owners have owned a home for a long time, those in the domain of financial gains will generally demand a higher price premium for their house, compared to those in the domain of financial losses (Fig. 1b).

This prediction is consistent with the findings of Akalis [34], who showed that financial losses are much more painful when they are experienced in the context of predominant gains than when they are experienced in the context of predominant losses, despite the fact that more is actually lost in the latter case than in the former. Those who have owned their homes for a long time and are in the domain of financial gains experience their home sale in the context of predominant 
Fig. 1 a Main effect of reference point [11]. A lower asking price in the gains domain (from $G 1$ to $G 2$ ) results in a smaller loss in utility (C1) compared to a lower asking price in the loss domain (from $L 1$ to $L 2$ ), which results in a larger loss in utility $(C 2)$. Therefore, individuals should be more willing to ask a lower price in the gains domain than in the loss domain, because it results in a smaller utility loss. b Effect of shifting the reference point to the right, due to a higher expected gain in the longer duration condition. A longer duration of ownership should shift the utility curve to the right, because the owner has an expectation of making a gain on the house, and anything lower than the expected gain is viewed as a loss, even if it is a positive outcome [31,32].

With the new curve, a lower asking price in the gains domain (from $G 1$ to $G 2$ ) results in a larger loss in utility $(\mathrm{Cl})$ compared to a lower asking price in the loss domain (from $L 1$ to $L 2$ ), which results in a smaller loss in utility $(C 2)$. Therefore, individuals should be more willing to ask a lower price in the loss domain than in the gains domain, because it will result in a smaller utility loss. Therefore, we expect a reference point $\times$ duration interaction. When the ownership is for a short duration, the owner should be more willing to ask a lower price in the gains domain than in the loss domain. However, when the ownership is for a long duration, the owner should be more willing to ask a lower in the loss domain than in the gains domain a

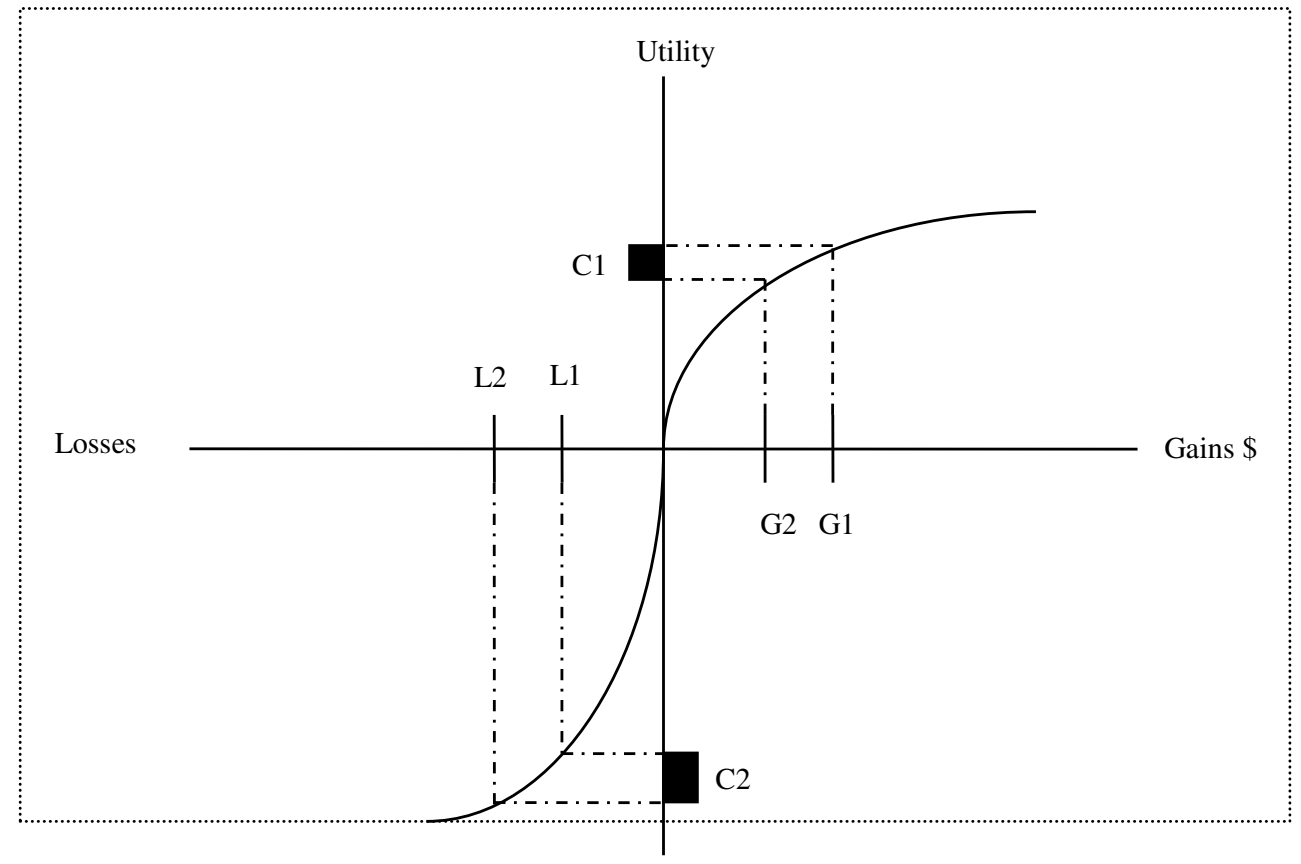

b

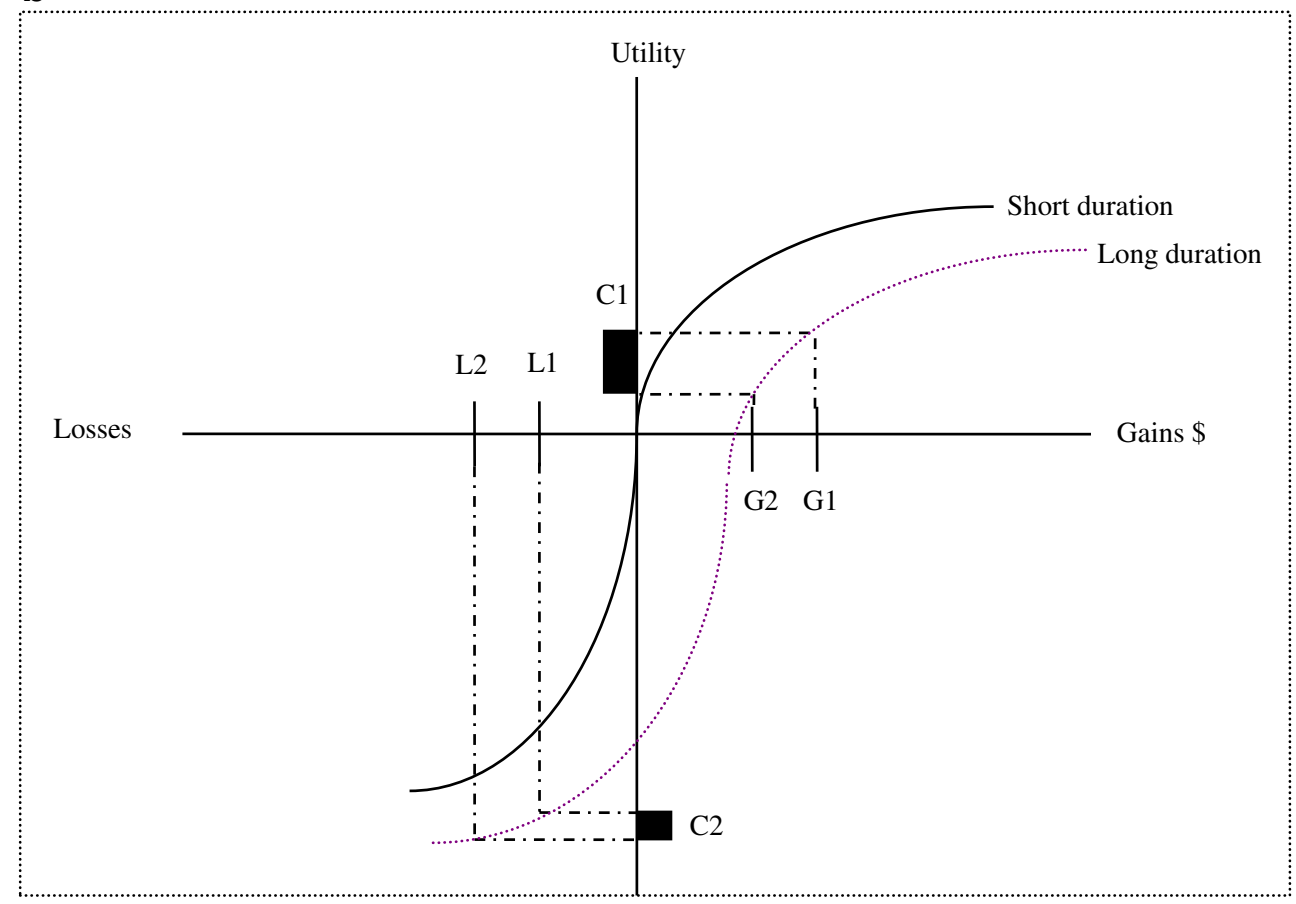

gains, and thus will experience any potential loss as particularly painful, resulting in higher price premiums demanded compared to people who have been in their home for a similar amount of time but are in the domain of financial losses. It is important to note that this prediction represents a reversal of what Prospect Theory would predict, namely that since losses loom larger than gains, individuals in the domain of losses, not the domain of gains, would demand a higher price premium.
On the other hand, consistent with Prospect Theory, sellers who have only owned a house for a short time should find financial losses deeply aversive, leading them to overly focus on their own purchase price, rather than current market prices, when establishing an asking price. Since losses loom larger than gains, at least in the short run, we expect these homeowners in the gains domain to ask for lower prices than homeowners in 
the losses domain. Thus, we expect a financial reference point $\times$ ownership duration interaction:

H1a After a long ownership duration, sellers should ask for higher prices when they are in the financial gains domain than when they are in the financial losses domain. However, after a short ownership duration, sellers should ask for lower prices when they are in the financial gains domain than when they are in the financial losses domain.

We expect ownership duration to have a different effect on sellers' price stickiness. Because sellers' initial asking prices tend to be emotionally laden, while buyers take a more rational view of the market, sellers are more likely to capitulate than buyers in repeated trials [20]. We thus expect stickiness to reflect a market correction, in which sellers in the long duration/gain and short duration/loss conditions realized their initial prices were too high, and quickly correct for their pricing errors. Indeed, recent research on the housing market has shown that when home sellers use comparable sale prices as a reference point they are likely to make price concessions [35]. Consequently, we expect our predictions related to initial asking price to reverse as sellers are forced to correct their prices:

H1b After a long ownership duration, sellers should be more willing to make price concessions when they are in the financial gains domain than when they are in the financial losses domain. However, after a short ownership duration, sellers should be less willing to make price concessions when they are in the financial gains domain than when they are in the financial losses domain.

\section{Emotional Reference Point and Ownership Duration Effects}

People perceive and judge material objects in social ways [36], and often make consumption decisions based on social factors, such as expressing uniqueness or conforming to others [37]. In particular, material possessions may be strongly associated with the self [38]. For example, individuals engage in possession rituals, such as decorating and renovating a home, in order to mark it as their own [39]. People who have lived in their houses longer are likely to have more memories and, thus, stronger emotional attachments to their homes. Possession attachment occurs when one's possessions evoke strong emotions and reflect one's identity and life story $[38,40]$. Possession attachment, unlike brand attachment, forms with singular, specific, irreplaceable objects such as baby blankets, photographs, souvenirs, and mementos [41,42], which are imbued with personal meaning [39]. When homeowners are positively attached to their homes such sacred items may be difficult to sell, particularly at market value [38]. People are likely to develop strong emotional connections with their homes, where they may have grown up, raised families, and/ or enjoyed holidays and long meals with friends [25,43]. A home may be viewed as a "personal archive or museum" ([38], p. 159), containing evidence of present and former selves. In fact, Belk [44] found that homes and favorite rooms were among the most salient items that people viewed as extensions of themselves. Such evidence may be viewed as positive (representing a desired or idealized self) or negative (representing an undesired self), resulting in either positively or negatively valenced feelings [45]. Psychologically, the positive memories associated with these homes are worth something to sellers, while negatively valenced possessions, such as those carrying memories of past mistakes or tragic life events, are easier to sell [45]. Indeed, recent work by Shu and Peck [46] demonstrates that traditional endowment effect findings may have an affective component.

In this research, we conceptualize positive emotional memories regarding the house as an emotional gain (similar to a financial gain in terms of Prospect Theory) and negative emotional memories about the house as an emotional loss. Previous research on Prospect Theory has attempted to take emotional attachment into account; however, it has tended to focus on the pain associated with the loss of an object, rather than on the positive utility enjoyed during the possession of an object (e.g., [18]). We, on the other hand, classify a positive ownership experience as a gain and a negative ownership experience as a loss. Thus, we are able to account for the fact that owners are often in a state of emotional gains or losses, even before entering into a potential exchange. Given that it has been shown that a priori emotions, both positive and negative, induced by an unrelated situation can influence economic decisions [47], we propose that the emotions associated with the ownership of the object in question should also impact economic decisions. As in the case of financial gains and losses, we expect that when the duration of ownership is short, a seller who has experienced an emotional gain should be more willing to make a concession (i.e., both ask for a lower price and lower the asking price more quickly) than a seller who has experienced an emotional loss, because losses loom larger than gains (see Fig. 2, short-term curve).

On the other hand, when the duration of home ownership is longer, a seller who has experienced an emotional gain should be less willing to make a concession than one who has experienced a loss due to a shift in the utility curve (see Fig. 2, long-term curve). Long-term owners in the domain of gains are likely to seek reimbursement for their high levels of emotional attachment to their homes. In contrast, sellers who have owned the home for a long period and are in the domain of emotional losses (i.e., they associate the home with negative experiences and the undesired self) should be more 


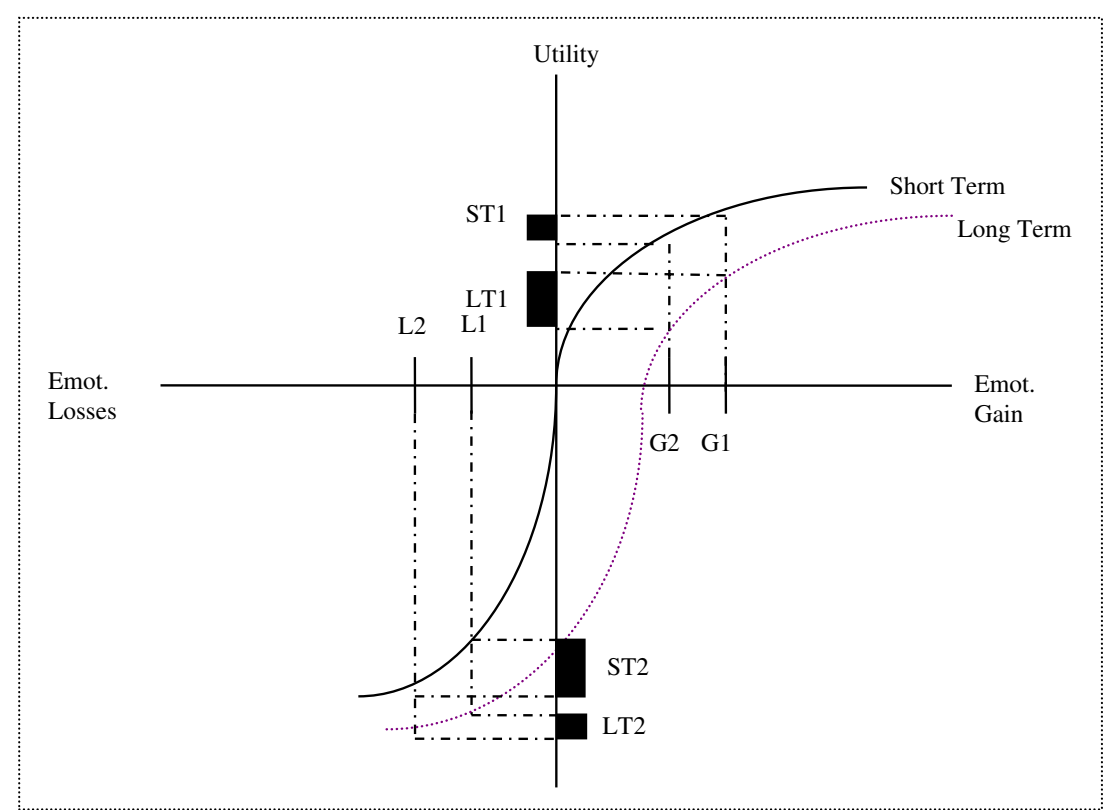

Fig. 2 The effects of emotional gains/losses. As with financial reference points, in the short term, a concession in the domain of emotional gains (from $G 1$ to $G 2$ ) results in a smaller loss in utility (ST1) compared to a concession in the domain of emotional losses (from L1 to L2) which results in a larger loss in utility (ST2). Therefore, in the short term, individuals should be more willing to make concessions when they are positively attached to the home, because they result in a smaller utility loss. In the long term, when emotional reference points are used, we again

willing to make a concession, because selling the house represents an unburdening of emotional baggage. While we predicted a reversal of this relationship on stickiness when considering financial gains and losses, we do not expect a similar reversal in the domain of emotional gains and losses. In the domain of financial gains and losses, the reversal on price stickiness reflects a correction in which sellers confront marketplace realities in the form of comparable selling prices [35]. In the case of emotional gains and losses, there is no objective external reference point that can guide sellers in their pricing. Consequently, we expect an emotional reference point $\times$ duration interaction for both asking price and price stickiness in which under a long ownership duration, sellers ask for higher prices and give fewer concessions in the domain of emotional gains compared to when they are in the domain of losses, and under a short ownership duration, sellers ask for lower prices and give more concessions in the domain of emotional gains compared to when they are in the domain of losses.

H2a After a long ownership duration, sellers should ask for higher prices when they are in the emotional gains domain than when they are in the emotional losses domain. However, after a short ownership duration, sellers should ask for lower prices when they are in the emotional gains domain than when they are in the emotional losses domain. expect the utility curve to shift to the right because selling the home represents a significant shift in the status quo. For individuals who have positive associations with the home, this change in the status quo is painful, leading any concessions ( $G 1$ to $G 2)$ to represent a significant loss in utility $(L T 1)$, while for individuals who have negative associations with the home, this change in the status quo represents an unburdening of emotional baggage causing any concessions ( $L 1$ to $L 2)$ to result in a minimal loss in utility (LT2)

H2b After a long ownership duration, sellers should be less willing to make price concessions (i.e., lower selling prices) when they are in the emotional gains domain than when they are in the emotional losses domain. However, after a short ownership duration, sellers should be more willing to make price concessions when they are in the emotional gains domain than when they are in the emotional losses domain.

We test these hypotheses through two studies. Study 1 is a field study, which tests the hypotheses using secondary data comprised of starting sales prices and price changes of a sample of actual home sellers in four different American housing markets (Phoenix, AZ; Minneapolis, MN; Philadelphia, PA; and Wilmington, DE). Study 2, conducted in the laboratory as a controlled experiment, tests the hypotheses by manipulating all three independent variables (ownership duration, financial reference point, and emotional reference point) and asking participants to play the role of sellers of a hypothetical home.

\section{Study 1}

Study 1 was a field study involving the analysis of real pricing decisions of US homeowners in the market to sell their homes. 


\subsection{Method and Measures}

We obtained a random sample of 637 homes that were listed for sale in the following metropolitan markets (including suburbs) as of January 2011: Phoenix, Minneapolis, Philadelphia, and Wilmington. We collected data using the ZipRealty website (www.ziprealty.com), which provides comprehensive local Multiple Listings Service (MLS) data. It is important to note that during this period, housing prices stabilized somewhat after having fallen precipitously during previous years, allowing for the inclusion of sellers facing losses and sellers facing gains on their home purchase. In compiling our dataset, we excluded any houses where the owner had owned the house less than a year before putting it on the market' in order to eliminate potential home "flippers". We also excluded houses which were bank owned, foreclosures, or short sales, as well those that were newly constructed and for sale by the builder.

For each listing, we collected the following variables: (1) home address; (2) number of bedrooms and bathrooms; (3) year the house was built; (4) square footage (size) of house; (5) date (month and year) the house was purchased by the current seller and its purchase price; (6) date when the house was listed for sale; (7) value of the house assessed by www.zillow.com, termed as "Zestimate" ; (8) the average prices of comparable houses sold in the same market (based on a total of up to 10 houses and normalized on a per-square foot basis); (9) value of the house assessed by www.eppraisal.com²; (10) the seller's initial asking price and the date when it was listed for sale; (11) changes in asking price made by the seller (up to five changes); and (12) current asking price and date when it was changed as of January 2011.

One limitation of using actual real-estate listings is that there is no explicit variable representing the seller's emotional reference point. To overcome this limitation, one of the study's authors examined each listing manually, paying attention to the pictures of the home posted on these websites by the seller. If one or more pictures had personal photographs of residents clearly visible in them, we coded the house as "emotional gain"; in cases where no personal photographs were visible, we coded the house as "emotional loss." Our logic in doing so was that personal photographs often contain images of family and friends and capture cherished moments. According to Belk [38], the interior décor of a home may be used to express one's true self. The use of personal photographs in home decorating provides a tangible means through which people put a personal touch on their living space and imbue it with positive memories [39]. Therefore, we reasoned that individuals who display personal photographs in their homes feel more attached to their homes, associating them with more positive memories than people who do not choose to display personal photographs (see also [48]). Furthermore, real-estate agents and stagers often recommend the removal of personal effects, including personal photographs, when selling a home. We reason that homeowners who have chosen to maintain these personal effects, despite advice to the contrary, are likely particularly attached to their homes.

From this information, we calculated the following variables for each listing: (1) ownership duration in months, as the time from the date of home purchase to date of sale listing; (2) the age of the house in years, from the year the house was built to the current year; (3) the current estimated value of the house, as an average of the Zestimate, prices of comparable houses sold recently and the eppraisal value (each normalized on a per square foot basis); (4) the average price asked, which is the average of all the asking prices since the house was listed; (5) the seller's current gain or loss on the house calculated as the difference between current estimated value of house and the seller's purchase price $^{3}$; and (6) whether the owner had experienced an emotional gain or an emotional loss in the home. For the analysis, we created a dummy variable called financial reference point that took the value 1 if the homeowner had enjoyed a gain (current estimated house value was greater than the seller's purchase price), and 0 if he/she had suffered a loss (current estimated value was less than the seller's purchase price). Finally, we conducted a median split (median duration $=82.2$ months) on the ownership duration to create two categories in the dataset which we refer to as short and long ownership durations in the analysis. The descriptive statistics for the variables used in the analysis are provided in Table 1, and the correlations between the variables are provided in Table 2.

\footnotetext{
${ }^{1}$ According to www.zillow.com, "The Zestimate home valuation is Zillow's estimated market value, computed using a proprietary formula. It is not an appraisal. It is a starting point in determining a home's value. The Zestimate is pulled from data; your real estate agent or appraiser physically inspects the home and takes special features, location, and market conditions into account."

${ }^{2}$ Like Zillow, eppraisal uses public record data from over 120 million homes and a proprietary formula to calculate a value estimate for a particular house.
}

\footnotetext{
${ }^{3}$ It is important to note that factoring in the realtor's commission (up to $6 \%$ ) could flip the financial reference point from a gain to a loss. To address this issue, we calculated an adjusted gain or loss variable with a $6 \%$ realtor's commission. In our dataset, only six houses flipped directions in this way. We repeated all the analyses reported herein using this adjusted gain or loss variable. Unsurprisingly, all the results remain substantively unchanged. These results are available upon request from the authors.
} 
Table 1 Descriptive statistics for variables in dataset, study $1(N=637)$

\begin{tabular}{lllll}
\hline Variable & Average & Std. Deviation & Minimum & Maximum \\
\hline Duration (months) & 114.4 & 81.5 & 16.9 & 676.1 \\
Purchase price & $\$ 249,654$ & $\$ 207,317$ & $\$ 8,000$ & $\$ 1,675,000$ \\
Initial asking price & $\$ 355,921$ & $\$ 349,757$ & $\$ 59,000$ & $\$ 3,490,000$ \\
Avg. asking price & $\$ 336,604$ & $\$ 323,542$ & $\$ 50,500$ & $\$ 3,142,500$ \\
Market value & $\$ 268,091$ & $\$ 186,796$ & $\$ 43,597$ & $\$ 1,371,001$ \\
Age of house (years) & 25.4 & 25.6 & 3 & 210 \\
Square footage & 2,246 & 1,095 & 606 & 7,684 \\
Gain or loss & $\$ 18,437$ & $\$ 162,461$ & $-\$ 955,023$ & $\$ 1,153,309$ \\
Adjusted. price premium (APP) & 0.284 & 0.386 & -0.780 & 3.27 \\
Days until first price change (DCA) & 82.1 & 82.6 & 1 & 683 \\
Adjusted change in asking price (ACAP) & 0.191 & 0.266 & 0 & 1.485 \\
\hline
\end{tabular}

To test the hypotheses regarding asking prices (H1a and $\mathrm{H} 2 \mathrm{a}$ ), we calculated the adjusted price premium (APP) as follows:

adjusted price premium $(\mathrm{APP})=\left(\frac{\text { average price asked-market value }}{\text { market value }}\right)$

APP is defined as the price premium asked by the homeowner as a percentage of the home's market value. Thus, a higher value of APP reflects a higher asking price and vice versa. The house prices in our dataset have a large range (see Table 1); APP normalizes these differences and allows us to make comparisons in pricing decisions across these different homeowners in percentage terms. Furthermore, to test the hypotheses regarding price stickiness ( $\mathrm{H} 1 \mathrm{~b}$ and $\mathrm{H} 2 \mathrm{~b}$ ), we used the time in days until first price change (DFC).

\subsection{Results}

Adjusted Price Premium We first considered the interactive effects of ownership duration and financial reference point. Results of a 2 (duration-long and short) $\times 2$ (financial reference point - gain and loss) ANOVA with APP as the dependent variable and the house's age and square footage included as covariates for control purposes revealed significant main effects of both duration, $F(1,630)=8.48, p<0.005$, and financial reference point, $F(1,630)=18.08$, $p<0.001$. The two-way interaction also emerged as significant, $F(1,630)=81.10, p<0.001$. Planned contrasts revealed that in the case of a long ownership duration, homeowners asked for a significantly higher APP in the gain condition $(M=0.573)$ than in the loss condition $(M=0.140, p<0.001)$. However, in the case of a short

Table 2 Correlations among variables in dataset, study $1(N=637)$

\begin{tabular}{|c|c|c|c|c|c|c|c|c|c|c|}
\hline & DUR & PPR & INIT & AVG & MKVAL & AGE & SQFT & GL & APP & DCA \\
\hline DUR & 1 & & & & & & & & & \\
\hline PPR & $-0.347^{\mathrm{a}}$ & 1 & & & & & & & & \\
\hline INIT & 0.033 & $0.611^{\mathrm{a}}$ & 1 & & & & & & & \\
\hline AVG & 0.032 & $0.617^{\mathrm{a}}$ & $0.997^{\mathrm{a}}$ & 1 & & & & & & \\
\hline MKVAL & 0.045 & $0.665^{\mathrm{a}}$ & $0.862^{\mathrm{a}}$ & $0.874^{\mathrm{a}}$ & 1 & & & & & \\
\hline AGE & $0.275^{\mathrm{a}}$ & $-0.260^{\mathrm{a}}$ & $-0.153^{\mathrm{a}}$ & $-0.158^{\mathrm{a}}$ & $-0.174^{\mathrm{a}}$ & 1 & & & & \\
\hline SQFT & -0.016 & $0.617^{\mathrm{a}}$ & $0.750^{\mathrm{a}}$ & $0.760^{\mathrm{a}}$ & $0.844^{\mathrm{a}}$ & $-0.198^{\mathrm{a}}$ & 1 & & & \\
\hline GL & $0.495^{\mathrm{a}}$ & $-0.512^{\mathrm{a}}$ & $0.212^{\mathrm{a}}$ & $0.217^{\mathrm{a}}$ & $0.302^{\mathrm{a}}$ & $0.131^{\mathrm{a}}$ & $0.182^{\mathrm{a}}$ & 1 & & \\
\hline APP & -0.036 & $0.224^{\mathrm{a}}$ & $0.539^{\mathrm{a}}$ & $0.525^{\mathrm{a}}$ & $0.163^{\mathrm{a}}$ & $-0.103^{\mathrm{a}}$ & $0.219^{\mathrm{a}}$ & $-0.099^{\mathrm{b}}$ & 1 & \\
\hline DCA & 0.050 & -0.014 & 0.027 & 0.029 & 0.022 & 0.037 & -0.054 & 0.044 & -0.006 & 1 \\
\hline
\end{tabular}

DUR ownership duration in months, $P P R$ purchase price of house, $I N I T$ initial asking price, $A V G$ average asking price, $M K V A L$ market value of house, $A G E$ age of the house in years, $S Q F T$ square-footage (size) of the house, $G L$ gain or loss on the house, $A P P$ adjusted price premium, $D C A$ days until first price change

${ }^{a}$ Correlation is significant at the 0.01 level (two-tailed)

${ }^{\mathrm{b}}$ Correlation is significant at the 0.05 level (two-tailed) 
ownership duration, homeowners asked for a significantly lower APP in the gain condition $(M=0.194)$ than in the loss condition $(M=0.334, p<0.05)$. These results are summarized in Fig. 3a and provide strong support for H1a.

Next, we examined the effects of emotional reference point. Results of a 2 (duration - long and short) $\times 2$ (emotional reference point-gain and loss) ANOVA with APP as the dependent variable and the house's age and square footage included as covariates for control purposes revealed a significant two-way interaction, $F(1,630)=4.97, p<0.05$. Neither main effect emerged as significant. Planned contrasts showed that for those with a long ownership duration, the difference in APP between those in the emotional gain $(M=0.290)$ and emotional loss $(M=0.237)$ was in the hypothesized direction, but not statistically significant, $F(1,332)=0.85, p \approx 0.35$. However, when homeowners had owned their house for a short duration, they asked for a significantly lower APP in
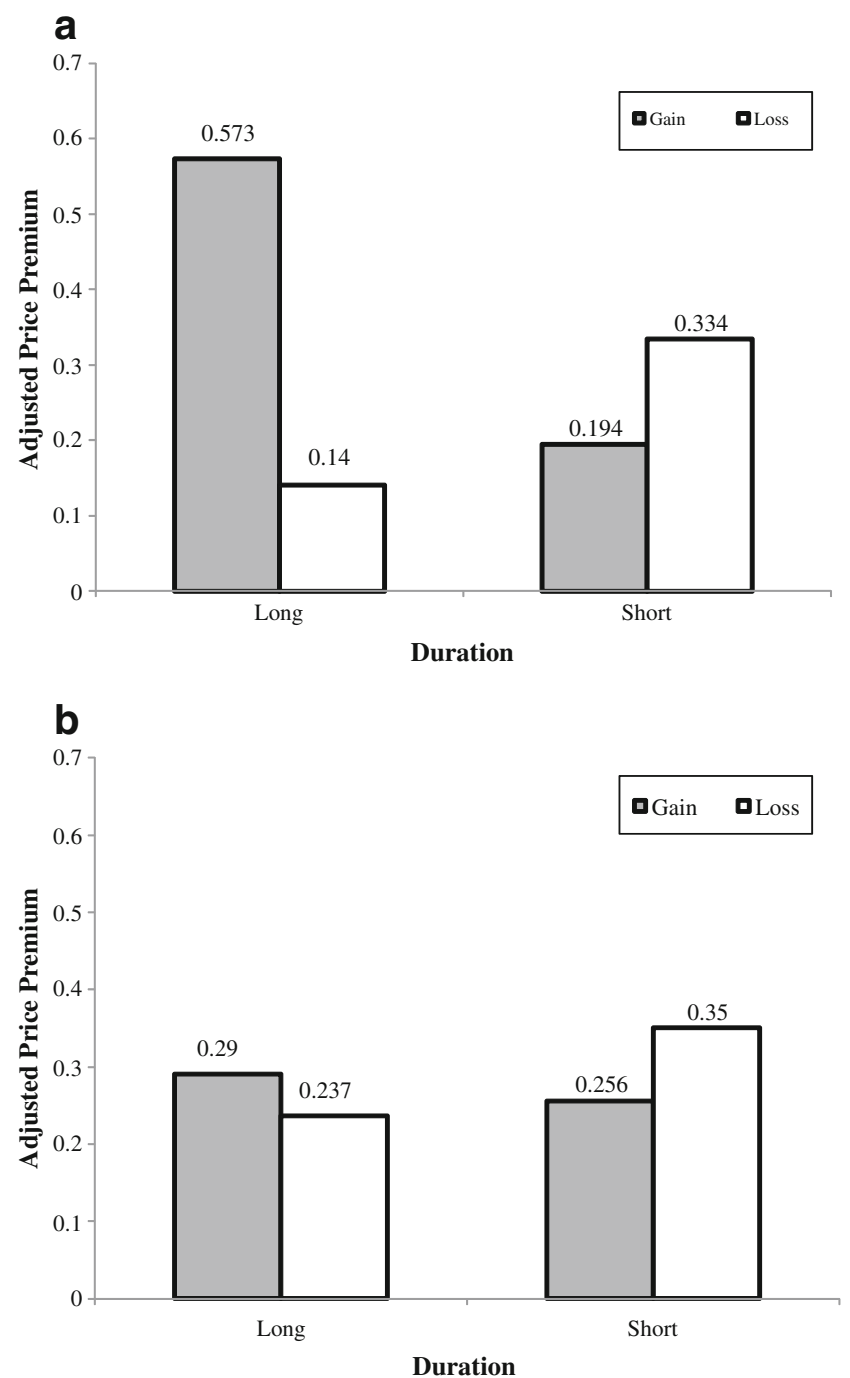

Fig. 3 Adjusted price premium by homeownership duration and a financial reference point and $\mathbf{b}$ emotional reference point, study 1 the gain condition $(M=0.256)$ compared to the loss condition $(M=0.350, p<0.05$; see Fig. 3b), providing partial support for $\mathrm{H} 2 \mathrm{a}$.

Days Until First Price Change We considered the interactive effects of ownership duration and financial reference point first. Results of a 2 (duration-long and short) $\times 2$ (financial reference point - gain and loss) ANOVA with DFC as the dependent variable and the house's age and square footage included as covariates for control purposes revealed a significant main effect of duration, $F(1,581)=6.63, p<0.01$, and a marginally significant main effect of financial reference point, $F(1,581)=3.3, p \approx 0.07$. Additionally, the two-way interaction emerged as significant, $F(1,581)=27.79, p<0.001$. In the case of a long ownership duration, sellers in the domain of financial gains lowered their asking prices more quickly ( $M=69$ days) than those in the domain of losses $(M=99$ days, $F(1,317)=$ $8.29, p<0.005)$. Moreover, in the case of a short ownership duration, sellers in the domain of gains took longer to lower their initial asking price ( $M=134$ days) than those in the domain of losses $(M=77$ days, $F(1,270)=21.13, p<0.001)$. These results are summarized in Fig. $4 \mathrm{a}$ and provide strong support for H1b.

Considering the duration $\times$ emotional reference point interaction next, a 2 (duration-long and short) $\times 2$ (emotional reference point - gain and loss) ANOVA with DCA as the dependent variable and the house's age and square footage included as covariates for control purposes revealed a significant two-way interaction, $F(1,581)=11.33, p<0.001$. In addition, the main effect of duration was significant, $F(1,581)=$ $6.78, p<0.01$, but that of emotional reference point was not, $F(1,581)=2.36, p>0.12$. Planned contrasts showed that under a long duration, sellers in the domain of emotional gains were directionally (but not significantly) slower in lowering their prices ( $M=80$ days) than those in the domain of emotional losses ( $M=68$ days), $F(1,313)=2.43, p>0.12$. However, under a short ownership duration, homeowners in the domain of emotional gains lowered their prices for the first time significantly faster ( $M=75$ days) than those in the domain of emotional losses $(M=109$ days, $F(1,266)=8.37, p<0.01)$. These results are summarized in Fig. $4 \mathrm{~b}$ and provide partial support for $\mathrm{H} 2 \mathrm{~b}$.

\subsection{Discussion}

By examining real pricing decisions of homeowners across four metropolitan US markets, these results provide useful insights into the interactive effects of ownership duration with financial and emotional reference points in both level of prices asked by homeowners (as assessed by adjusted price premium) and their stickiness (as measured by days until first price change and adjusted change in asking price). Our findings support hypotheses 1a, 1b, 2a, and $2 \mathrm{~b}$. 

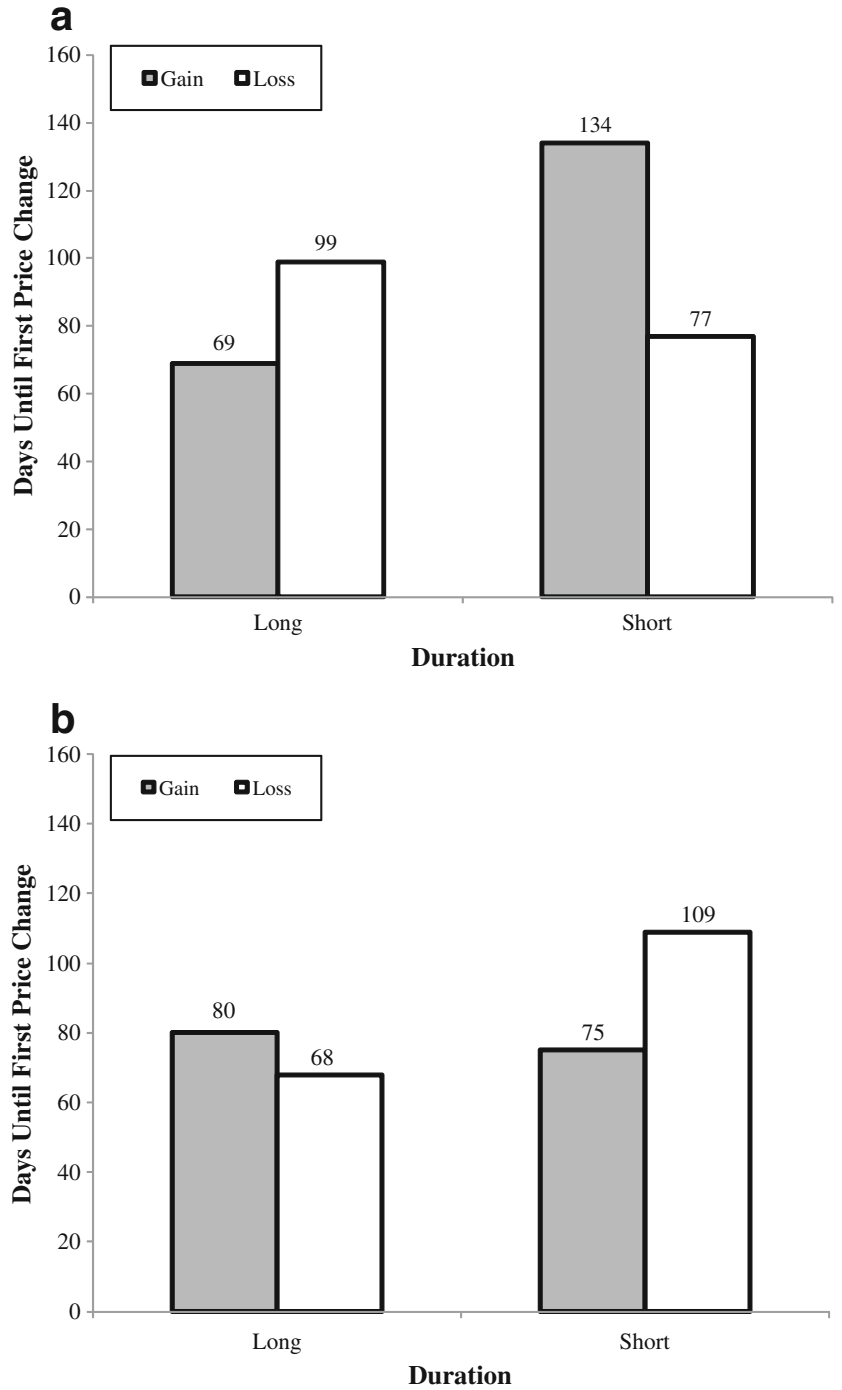

Fig. 4 Days until first price change by homeownership duration and a financial reference point and $\mathbf{b}$ emotional reference point, study 1

We find the pattern of results to be particularly interesting in the case of price stickiness, given that sellers had different reactions depending on whether their losses/gains were financial or emotional. In the case of financial losses/gains, in addition to likely reflecting a market correction, it is also possible that the length of ownership changes perceptions of the nature of the housing market. Owners who have been in their homes for a long period of time may be more likely to take a broader view of the market (having been exposed to its ups and downs) and thus are more likely to view the market as malleable (e.g., [49]), while those who have only owned their home for a short period of time may be likely to take a narrower view of the market and thus are likely to view the market as fixed, and consequently be more likely to expect current trends to continue.

In the financial gains domain, although long-time owners initially list their homes at much higher prices when compared to those who have owned their home for a shorter time, it is possible that they are more willing to lower prices to get the house sold and (still) earn a profit, resulting in less price stickiness. Because long-term owners are more likely to view the market as changeable, when they receive feedback that their initial asking prices are too high (i.e., the bid is rejected), they may act more like short-term owners and give larger concessions. In other words, when in the domain of financial gains, long-term owners' greater willingness to lower their asking prices can be interpreted as a hedge against possible future unfavorable fluctuations in the market.

In contrast, in the domain of financial losses, having set prices lower to begin with, it is possible that long-time owners are more motivated to avoid further monetary losses and therefore are less willing to lower asking prices compared to those who have purchased the house more recently (e.g., [50,51]). Again, because long-term owners take a broader view, this greater reluctance to further drop prices, or "stickiness," reflects a perception that the market is changeable. Thus, in the domain of financial losses, we see higher price stickiness for long-time owners than for short-term owners. In contrast, the reason that we see a different and predicted pattern of results for emotional reference points is that the concept of market malleability is not relevant when considering emotional reference points. In other words, whether you have owned a home for a long or a short period, there is no reason to expect the memories you already have in the home to change for the better or the worse, allowing us to find support for $\mathrm{H} 2 \mathrm{~b}$. This appears to be an instance where financial and emotional reference points interact in different ways with the homeowners' ownership duration in influencing pricing decisions.

One limitation of this field study is that because of its observational nature, emotional reference point was captured in an indirect way, based on whether the homeowner displayed personal photographs of oneself and family members in the listing. It is important to verify and replicate these results in a more controlled setting. Accordingly, study 2 was conducted in the laboratory.

\section{Study 2}

\subsection{Method and Participants}

We conducted study 2 as a controlled experiment in the laboratory to investigate the impact of the ownership duration, financial reference point, and emotional reference point on housing valuations and price stickiness. We conducted a 2 (ownership duration - short $(1$ year $)$ vs. long $(8$ years $)) \times 2$ (financial reference point — gain vs. loss) $\times 2$ (emotional reference point - positive vs. negative) experiment, involving 98 undergraduate participants who received partial course credit for their participation. 
Following a procedure similar to that used by Kristensen and Gärling [52], we asked participants to play home sellers in a hypothetical housing market. They received hypothetical information about their own home, which they were trying to sell. The experimental materials instructed participants to imagine that they currently owned a house and were interested in selling it. Details of the house specified that the participant had either owned the house for 1 year (short duration) or 8 years (long duration), was either positively (domain of emotional gains) or negatively (domain of emotional losses) attached to the house, and had paid either $\$ 175,000$ (gains domain) or $\$ 355,000$ (losses domain) for the house (see the sample materials in the Appendix).

In the emotional gains condition, we instructed participants, "You feel very attached to the house. You have a lot of fond memories from living there." In contrast, those in the emotional losses condition were told, "You don't feel very attached to the house. It reminds you of past mistakes and you are ready to move on." The instructions also gave recent comparable home sales $(M=\$ 265,000)$ and asked participants to provide an asking price, after which they would learn whether the hypothetical buyer had accepted the asking price. If the buyer did not accept the price, the participant had the opportunity to change the price (or keep it the same) for up to four more rounds. Using repeated trials is a well-established method in experimental economics for revealing buyers' and sellers' true values for items, as well as examining learning over time [20,53]. This method also allowed us to measure price stickiness as the total change in the seller's price over the five rounds of the game. Additionally, we provided monetary incentives in order to ensure that participants gave their best estimates of their true valuations. They received $\$ 1$ for every $\$ 100,000$ of the final selling price. We used a computer algorithm to play the role of the hypothetical buyer. Since the average of recent comparable sales was $\$ 265,000$, if the seller provided a price above $\$ 265,000$, the house did not sell. At any price at or below $\$ 265,000$, the house was sold and they received $0.001 \%$ of the final selling price.

\subsection{Results}

Initial Asking Price The results of a 2 (ownership durationshort vs. long) $\times 2$ (financial reference point-gains vs. losses) $\times 2$ (emotional reference point - positive vs. negative) ANOVA, with initial asking price as the dependent variable, revealed that although none of the main effects were significant, two of the three two-way interactions, ownership duration $\times$ financial reference point, $F(1,97)=4.45, p<0.05$, and ownership duration $\times$ emotional reference point, $F(1,97)=$ 5.91, $p<0.02$, emerged as significant.

Examining the ownership duration $\times$ financial reference point interaction first, contrasts revealed that after a long ownership duration, participants in the financial gains condition listed their houses at a significantly higher price $(M=\$ 313,000)$ compared to participants in the financial losses condition $(M=\$ 288,600, F(1,46)=4.13, p<0.05)$. In contrast, after a short ownership duration, participants in the financial gains condition listed their houses at a significantly lower price $(M=\$ 289,400)$ compared to participants in the financial losses condition $(M=\$ 325,300, F(1,48)=7.34, p<0.01)$. Figure 5a graphically illustrates these findings, which support H1a.

Examining the ownership duration $\times$ emotional reference point interaction next, contrasts revealed that after a long ownership duration, participants in the emotional gains condition asked for significantly higher prices $(M=325,720)$ than participants in the emotional losses condition $(M=\$ 291,304$, $F(1,46)=5.89, p<0.05)$. After a short ownership duration, participants in the emotional gain condition asked for slightly but not significantly lower prices $(M=\$ 303,041)$ than participants in the emotional loss condition $(M=\$ 315,531$, $F(1,48)=0.79, p>0.35)$. Figure 5 b graphically summarizes these results, which provide partial support for $\mathrm{H} 2 \mathrm{a}$.

Total Change In Asking Price We also analyzed the effects of the three independent factors on total change in asking price, which we defined as the difference in initial asking price and the lowest asking price (either the asking price in the fifth and last round, or the asking price which was accepted), controlling for initial asking price. For those participants whose first bid was accepted, the total change in asking price was calculated to be zero. The results of an ownership duration $\times$ financial reference point $\times$ emotional reference point ANCOVA, controlling for initial asking price, revealed that none of the three main effects was significant. However, two of the two-way interactions, duration $\times$ financial reference point, $F(1,97)=4.53, p<0.05$, and duration $\times$ emotional reference point, $F(1,97)=5.33, p<0.05$, emerged as significant.

Considering the ownership duration $\times$ financial reference point interaction first, contrasts revealed that after a long ownership duration, participants in the financial gains condition demonstrated similar stickiness (as measured by total change in price) to those in the financial losses condition $\left(M_{\text {FinancialGain }}=\$ 52,939\right.$ vs. $M_{\text {FinancialLoss }}=\$ 49,304$, $F(1,41)=0.81, p>0.90$. After a short ownership duration, participants in the financial gains condition demonstrated stickier asking prices (i.e., they had a much lower total change in price) $(M=\$ 30,640)$ than participants in the financial losses condition $(M=\$ 73,678, F(1,42)=4.23, p<0.05)$. These results, which are graphically summarized in Fig. 6a, provide partial support for $\mathrm{H} 1 \mathrm{~b}$.

We considered the ownership duration $\times$ emotional reference point interaction next. After a long ownership duration, participants in the domain of emotional gains were significantly more sticky, in other words changed their asking price to a lesser degree $(M=\$ 37,391)$, than participants in the domain of emotional losses $(M=\$ 63,900, F(1,40)=3.79$, 
Fig. 5 Initial asking price by homeownership duration and $\mathbf{a}$ financial reference point and $\mathbf{b}$ emotional reference point, study 2 a

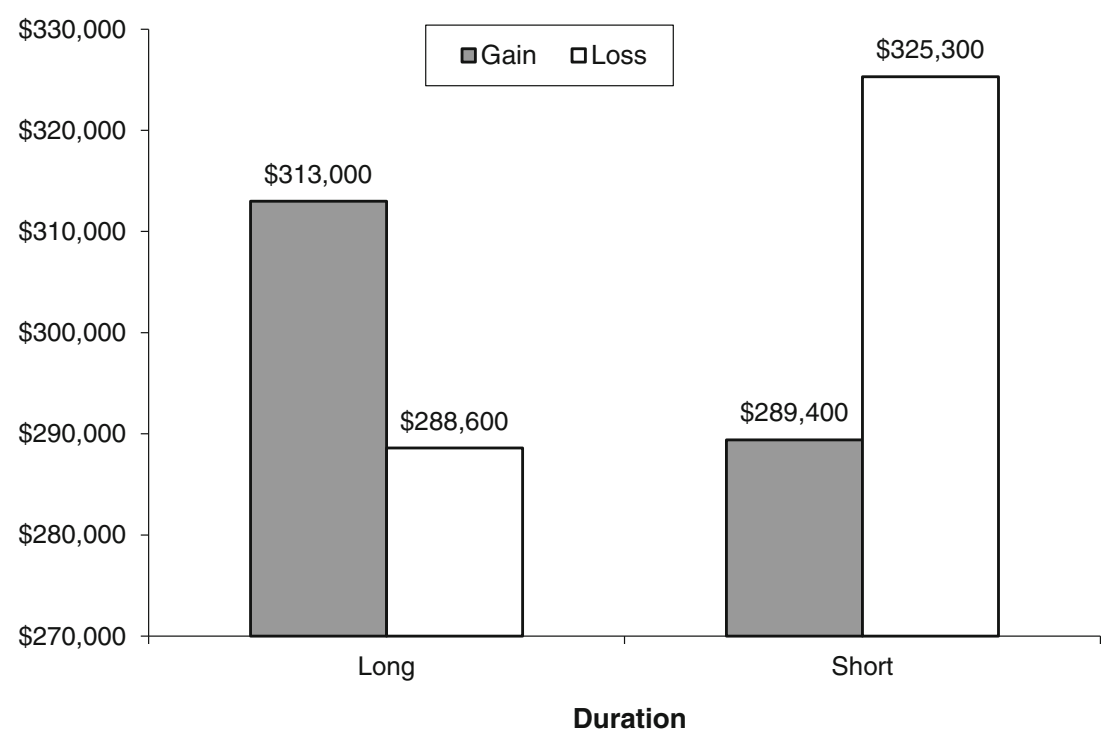

b

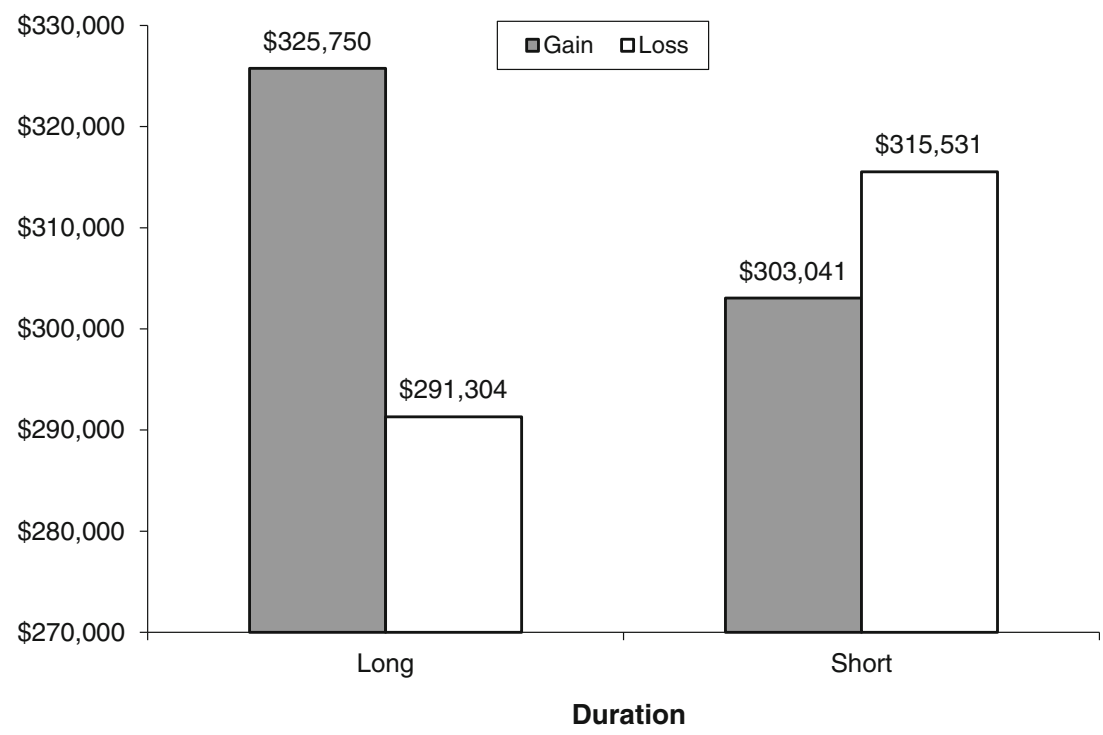

$p=0.05$ ). After a short ownership duration, participants in the domain of emotional gains were directionally less sticky $(M=\$ 59,080)$ than participants in the domain of emotional losses $(M=\$ 43,962, F(1,39)=2.39, p>0.13)$ but the difference did not emerge as statistically significant. These results are graphically summarized in Fig. 6b, and provide partial support for $\mathrm{H} 2 \mathrm{~b}$.

\section{Discussion}

These results provide a replication of the results found in our field study in a more controlled environment. As predicted, we found additional support for the interactive effects of ownership duration with both financial and emotional reference points in affecting initial asking price and the predicted interactive effects of ownership duration with both financial and emotional reference point in affecting change in asking price.

\section{General Discussion and Conclusion}

Our goal in this research was to obtain a better understanding of homeowners' decision making when pricing their homes for sale. To this end, we examined the interactive effects of the duration of ownership and changes in financial and emotional reference points on decisions regarding initial asking prices and concessions made by the homeowner. Convergent results from a field study involving actual pricing decisions of homeowners from four US metropolitan markets and a 

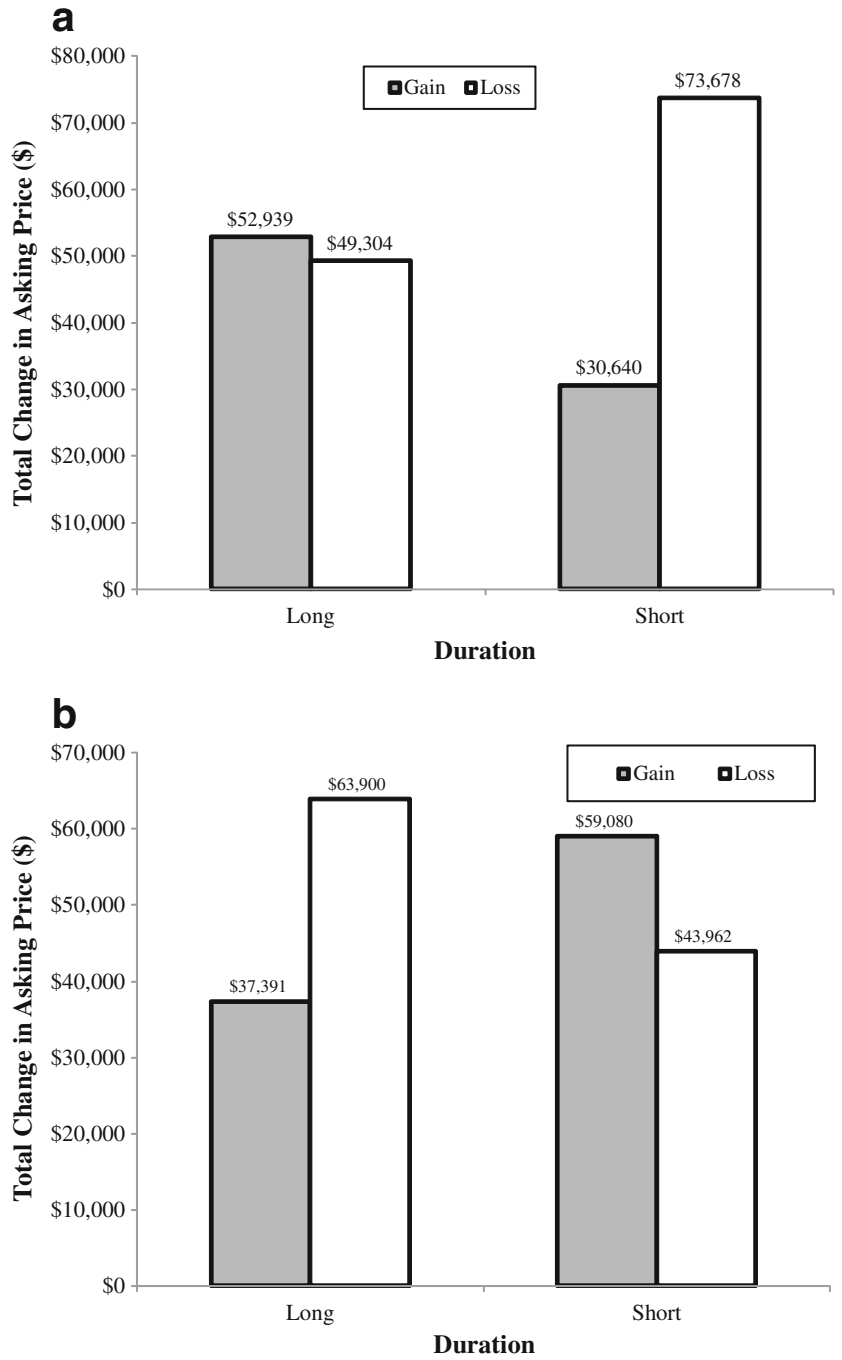

Fig. 6 Total change in asking price by homeownership duration and a financial reference point and $\mathbf{b}$ emotional reference point, study 2

controlled laboratory experiment revealed that for a relatively long duration of home ownership, sellers initially ask for higher prices when they stand to make money on the sale than when they will lose money, but show the opposite pattern for short ownership duration. Such a pattern is inconsistent with the basic loss aversion effect predicted by Prospect Theory [11], but is consistent with our proposed framework, which posits that owning a house for a long duration shifts owner reactions to financial losses and gains. We found a similar pattern of results when we examined the effects of emotional reference points (the accumulation of positive vs. negative memories) in conjunction with duration of home ownership. In addition to initial asking prices, we also examined price stickiness, defined as how much homeowners lowered prices from their initial levels. While we found that emotional reference point and ownership duration interact in a similar manner on both initial asking price and price stickiness, we predicted and found a different relationship in the case of emotional vs. financial losses/gains on price stickiness. As predicted, we found that in the case of emotional gains/losses, ownership duration has a similar effect on both initial asking price and stickiness. Specifically, when owners have enjoyed a long and positive relationship with their home they not only expect to be well compensated for their idealized home, but are unwilling to budge in their prices. However, when the relationship has been short and sweet, sellers are not only willing to ask a little less up front, but are willing to drop their price more quickly compared to when the relationship has been brief and rocky. On the other hand, we found a different pattern for financial losses/gains, reflecting a market correction and possibly perceived malleability of the market. We find it particularly interesting that while over time, sellers are able to adjust for their biases in the case of financial gains and losses, likely because they are getting concrete feedback from the marketplace, they are unable to do so in the case of emotional gains and losses.

The current research offers several theoretical contributions to the existing literature. First, whereas prior articles have investigated moderators and boundary conditions of the endowment effect (e.g., $[14,15,17])$, we instead chose to focus exclusively on sellers' biases in setting asking prices and then adjusting them, particularly in a declining market. To do this, we built on behavioral decision making, sociology, and consumer culture theory literature to form predictions about how the seller's financial reference point, relative to the home's purchase price, and emotional reference point, as captured by attachment to the home, might influence these evaluations. While most negotiations between home buyers and sellers demonstrate some evidence of endowment gaps, we hypothesized and found that ownership duration, in conjunction with financial and emotional reference points can reverse these effects.

From a practical standpoint, we believe the results from our studies have the potential to inform real estate professionals and financial services providers regarding issues such as how their customers, who are homeowners, set prices in the housing market, and which persuasion strategies may be effective for encouraging sales. Two of the three variables we examined, ownership duration and financial reference point (operationalized via knowledge of the homeowner's purchase price), are available to these Realtors and service providers from publicly available data sources such as Zillow.com. The third variable, emotional reference point, can be ascertained through the preliminary interview with the home owner. It could even be inferred by observing the homeowner's possessions (as we did in study 1). Realtors may then be able to use this information to identify homeowners that may be more likely to price aggressively (i.e., ask for higher-than-warranted prices), and prepare to persuade them to price reasonably, for example, by emphasizing sales of lower-priced homes in their neighborhood. 
Furthermore, our results provide potentially useful guidance to policy makers seeking to alleviate the housing crisis. Thus far, the majority of efforts have focused on either providing home buyers with additional means to purchase homes, in an effort to reduce the housing inventory, by providing incentives and reducing interest rates, or on providing relief to homeowners facing potential foreclosure. Another option is to offer incentives to sellers to make greater concessions, thus hastening the end of the crisis. For example, our findings regarding homeowner decision making in the gains domain suggest that long-term owners who stand to make money on the sale of their homes are actually the most likely to hold out for higher prices. Perhaps incentives such as a reduction in capital gains taxes for those who have owned their homes for a certain period of time might induce these sellers to lower their asking prices to hasten the sale.

One limitation of the current research is that we did not study the impact of homeowners' equity on their pricing decisions. Another viable reference point for many homeowners could be the amount of their outstanding liability on the house, operationalized as the sum of the current mortgage balance and other secured loans taken against the home (Genovese \& Mayer [54]). At one point during the height of the housing market crisis, as many as 11 million (one in five) US households with mortgages were "underwater," defined as owing more on their mortgages than their homes are worth (eCreditDaily [55]). Our findings are particularly relevant for these homeowners, who are at high risk of foreclosing on their homes if they are unable to sell them. The Obama Administration's Home Affordable Modification Program (HAMP) provides incentives to banks to modify these homeowners' interest rates, but far fewer homeowners qualified for such modifications [56]. Another proposed alternative is principal reduction, in which the banks would reduce mortgage balance amounts for struggling homeowners. This proposal is highly controversial due to concerns regarding moral hazard; many banks fear that homeowners will stop making mortgage payments in order to qualify for principal reduction [8]. Our findings may offer some direction to lenders considering principal reduction for their mortgage holders. More specifically, short-term homeowners in the domain of financial losses in our studies appear to represent the largest risk of default since they are most likely to demand unreasonably high prices. Therefore, banks might focus their efforts on this segment of consumers by encouraging either short sales or principal reduction programs. Such actions might move short-term owners from the domain of losses domain to the domain of gains, thereby lowering their asking prices.

Acknowledgments The authors would like to thank John Lastovicka and Steve Nowlis for their insightful comments and Rachel Wheeler for her help with data collection for the field study.

\section{Appendix}

Experimental materials for Study 2

Imagine that you own the house pictured below.

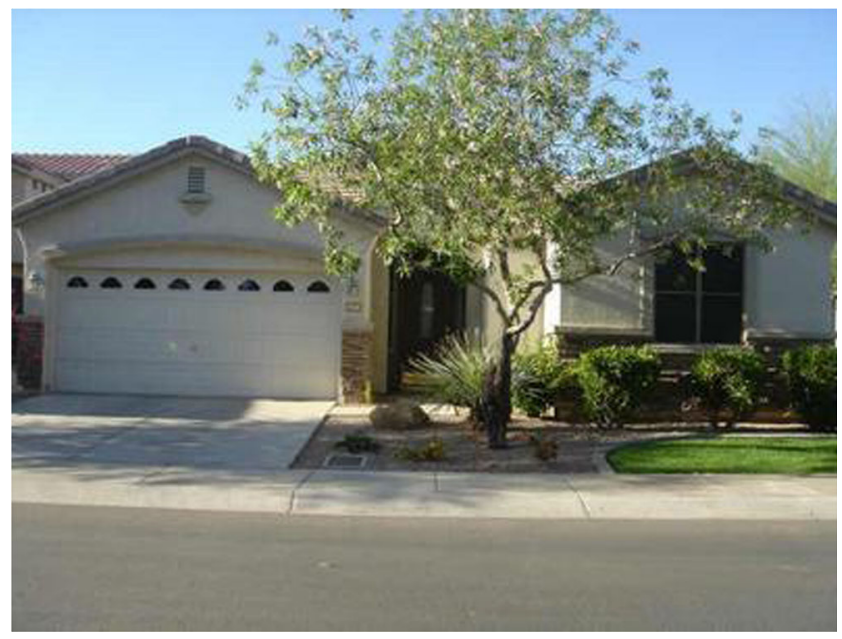

- Your house has three bedrooms, two baths, is a singlelevel, single-family detached home.

- It has approximately $1,600 \mathrm{ft}^{2}$ of living area with a two-car garage.

- It is on a corner lot in a gated community.

- There is a heated community pool and a heated community spa in the neighborhood.

- The house was built in 1994.

Imagine that you have lived in this house for 1 year (8 years), and paid $\$ 175,000(\$ 355,000)$. You feel very attached to the house. You have a lot of fond memories from living there. (You don't feel very attached to the house. It reminds you of past mistakes and you are ready to move on.)

Other houses in the neighborhood are similar to your house, ranging in size from 1,250 to 1,950 square feet.

Your realtor has told you that over the past 8 weeks, three houses comparable to yours in your neighborhood have sold for $\$ 248,000, \$ 277,000$, and $\$ 271,000$.

\section{References}

1. Bernstein P (2008) What happens if we're wrong? New York Times, Economic View. June 22

2. Isidore C (2008) How we got here: it's housing, stupid. CNNMoney.com. September 17. http://money.cnn.com/2008/09/17/ news/economy/housing/index.htm

3. Glaeser EL, Sinai T (2013) Postmortem for a housing crash. Hous Financ Crisis 1(2):117-128 
4. Streitfeld D (2010) Housing fades as a means to build wealth, analysts say. New York Times, August 22

5. Case KE, Quigley JM (2007) How housing booms unwind: income effects, wealth effects, and sticky prices. Paper presented at a joint session of the American Economic Association and the American Real Estate and Urban Economics Association, Chicago

6. Case KE, Shiller RJ (1988) The behavior of home buyers in boom and post boom markets. New England Economic Review, November/ December, 29-46

7. Case KE, Shiller RJ (2003) Is there a bubble in the housing market? Brook Pap Econ Act 2:299-342

8. Nocera J (2011) To fix the housing crisis, see the data. New York Times, November 4

9. Liu CH, Nowak A, Rosenthal S (2014) Bubbles, post-crash dynamics, and the housing market. Working paper, Syracuse University

10. Mellers BA, Ritov I (2010) How beliefs influence the relative magnitude of pleasure and pain. J Behav Decis Mak 23:369-382

11. Kahneman D, Tversky A (1979) Prospect theory: an analysis of decision under risk. Econometrica 47:263-291

12. Kahneman D, Knetsch JL, Thaler RH (1990) Experimental tests of the endowment effect and the Coase theorem. J Polit Econ 99: $1325-1348$

13. Strahilevitz MA, Loewenstein G (1998) The effect of ownership history on the valuation of objects. J Consum Res 25:276-289

14. Dommer SL, Swaminathan V (2013) Explaining the endowment effect through ownership: the role of identity, gender, and selfthreat. J Consum Res 39(5):1034-1050

15. Nayakankuppam D, Mishra A (2005) The endowment effect: rosetinted and dark-tinted glasses. J Consum Res 32:390-395

16. Saqib NU, Frohlich N, Bruning E (2010) The influence of involvement on the endowment effect: the moveable value function. $\mathrm{J}$ Consum Psychol 20(3):355-368

17. Aggarwal P, Zhang M (2006) The moderating effect of relationship norm salience on consumers' loss aversion. J Consum Res 33(3): 413-419

18. Carmon Z, Ariely D (2000) Focusing on the forgone: how value can appear so different to buyers and sellers. J Consum Res 27(3): $360-370$

19. Irmak C, Wakslak CJ, Trope Y (2013) Selling the forest, buying the trees: the effect of construal level on seller-buyer price discrepancy. $\mathrm{J}$ Consum Res 40(2):284-297

20. Coursey DL, Hovis JL, Schulze WD (1987) The disparity between willingness to accept and willingness to pay measures of value. Q J Econ 102:679-690

21. Chernikoff H (2009) Sliding Manhattan home prices give sellers shivers. Reuters UK, Available online at: http://uk.reuters.com/ article/idUKLNE53000N20090401

22. Kell J (2010) S\&P raises risk of moving M/I homes to highly speculative. Wall Street Journal, September 28

23. Bils M, Klenow PJ (2004) Some evidence on the importance of sticky prices. J Polit Econ 102:947-985

24. Carlton DW (1986) Rigidity of prices. Am Econ Rev 76(4): $637-658$

25. Leonhardt D (2008) Be it ever so illogical: homeowners who won't cut the price. New York Times, Economic Scene, March 26

26. Price D (2008) Ready to rumble: buyers and sellers both refuse to give ground as power in the housing market shifts. The News and Observer (Raleigh, NC). May 18

27. Mowen JC, Mowen MM (1991) Time and outcome valuation: implications for marketing decision making. J Mark 4:54-62

28. Blount S, Thomas-Hunt MC, Neale MA (1996) The price is rightor is it? A reference point model of two-party price negotiations. Organ Behav Hum Decis Process 1:1-12
29. Buchan NR, Croson RTA, Johnson EJ (2004) When do fair beliefs influence bargaining behavior? Experimental bargaining in Japan and the United States. J Consum Res 31:181-190

30. Chapman GB (2000) Preferences for improving and declining sequences of health outcomes. J Behav Decis Mak 13(2):203-218

31. Carnevale PJ (2008) Positive affect and decision frame in negotiation. Group Decis Negot 17:51-63

32. Hoch SJ, Loewenstein GF (1991) Time-inconsistent preferences and consumer self-control. J Consum Res 17:492-507

33. Carmon Z, Wertenbroch K, Zeelenberg M (2003) Option attachment: when deliberating makes choosing feel like losing. J Consum Res 30: $15-29$

34. Akalis SA (2008) A new spin on losses looming larger than gains: asymmetric implicit associations from slot machine experience. $\mathrm{J}$ Behav Decis Mak 21:378-398

35. Witte CL, Grünhagen M, Gentry JW (2008) An empirical investigation of framing effects in negotiations: a study of single-family home sales. Psychol Mark 25(5):465-484

36. Beggan JK (1992) On the social nature of nonsocial perception: the mere ownership effect. J Pers Soc Psychol 62(2): 229-237

37. Amaldoss W, Jain S (2005) Pricing of conspicuous goods: a competitive analysis of social effects. J Mark Res 42(1):30-42

38. Belk RW (1988) Possessions and the extended self. J Consum Res 15:139-168

39. McCracken G (1986) Culture and consumption: a theoretical account of the structure and movement of the cultural meaning of consumer goods. J Consum Res 13:71-84

40. Kleine SS, Kleine RE III, Allen CT (1995) How is a possession 'me' or 'not me?' Characterizing types and an antecedent of material possession attachment. J Consum Res 22: 327-343

41. Belk RW (1992) Attachment to possessions. In: Altman I, Low SM (eds) Place attachment. Plenum, New York, pp 37-55

42. Kleine SS, Baker SM (2004) An integrative review of material possession attachment. Acad Mark Sci Rev 1:1-35

43. Rhodes E (2008) Home sales dive, but prices don't; 'stickiness' factor: owners stick to asking price despite low sales, high inventory in King County. Seattle Times, April 5

44. Belk RW (1987) Identity and the relevance of market, personal and community objects. In: Umiker-Sebeok J (ed) Marketing and semiotics: new directions in the study of signs for sale. Mouton de Gruyter, Berlin, pp 151-164

45. Lastovicka JL, Fernandez KV (2005) Three paths to disposition: the movement of meaningful possessions to strangers. J Consum Res 31: 813-823

46. Shu SB, Peck J (2011) Psychological ownership and affective reaction: emotional attachment process variables and the endowment effect. J Consum Psychol 21(4):439-452

47. Lerner JS, Small DA, Loewenstein G (2004) Heart strings and purse strings: carryover effects of emotions on economic decisions. Psychol Sci 15(5):337-341

48. Wallendorf M, Arnould EJ (1988) My favorite things: a cross-cultural inquiry into object attachment, possessiveness, and social linkage. J Consum Res 14(4):531-547

49. Flavin M, Yamashita T (2000) Owner occupied housing and the composition of the household portfolio. Am Econ Rev 92(1): $345-362$

50. Bazerman MH, Magliozzi T, Neale MA (1985) Integrative bargaining in a competitive market. Organ Behav Hum Decis Process 34:294-313

51. Kahneman D (1992) Reference points, anchors, norms, and mixed feelings. Organ Behav Hum Decis Process 51(2):296-312

52. Kristensen H, Gärling T (1997) Determinants of buyers' aspiration and reservation price. J Econ Psychol 18(5):487503 
53. Weber M, Camerer CF (1998) The disposition effect in securities trading: an experimental analysis. J Econ Behav Organ 33(2): 167-184

54. Genesove D, Mayer C (2001) Loss aversion and seller behavior: evidence from the housing market. The Quarterly Journal of Economics, November, 1233-60
55. eCredit Daily (2010). Negative equity crisis: harbinger of foreclosures to come? eCreditDaily.com. February 12. http:// ecreditdaily.com/2010/02/negative-equity-crisis-harbingerforeclosures/

56. Nelson AA (2010) Bailing out underwater mortgages. SPEA Insights, May 2010 